\title{
Progress on the exploitation of urban underground space (UUS) in China
}

\author{
Jie Liu ${ }^{1}$, Ling Zeng ${ }^{2}$, and Hanbing Bian ${ }^{3, *}$ \\ ${ }^{1}$ School of Traffic \& Transportation Engineering, Changsha University of Science \& Technology, \\ Changsha 410114, Hunan, China \\ ${ }^{2}$ School of Civil Engineering, Changsha University of Science \& Technology, Changsha 410114, \\ Hunan, China \\ ${ }^{3}$ Laboratoire de Génie Civil et géo-Environnement, Université de Lille, 5900 Lille, France
}

\begin{abstract}
With the rapid urbanization in China, the disasters and the problems related with the urban underground space (UUS) exploitation increase. As an inevitable choice for sustainable urban development, how to increase the efficiency of the underground space use and augment the resilience of the UUS are the main challenges today in China. In this study, the strategic demands of the sustainable urban development on the underground space exploitation in Chinese cities have been analyzed and discussed. The associated problems and difficulties on the underground space exploitation were discussed. Moreover, the possible solutions were also proposed.
\end{abstract}

\section{Introduction}

The urban underground space (UUS) refers to the space below the ground available for human development and utilization [1,2]. With the 30-year's rapid economic development, the urbanization has been sufficiently developed in China. In the same time, so many problems associated with the urbanization are also emerged. The most important is the shortage of the land resources and the green space in the urban area [3]. The exploitation of UUS resources is an inevitable choice for the sustainable urbanization.

\footnotetext{
* Corresponding author: hanbing. bian@univ-lille.fr
} 
The China, as well as the human all over the world, has long history for underground exploitation. Not only for the space (habitation, reservoir, etc.), but also for the resources (water, energies, miners, etc.). However, these experiences are far away from todays demands. Comparing with the modern urbanization, the experiences for the exploitation of UUS in China is relative late. The first metro in China opened in 1971, while the first metro in London is 1863. Even though, the development of UUS is very rapid. The first line of metro in Shanghai is 1993. Today, the metro of Shanghai is longer and more complicated than that of London's. However, with the rapid development, so many problems related the exploitation of the UUS has been unveiled. These problems concern the Chinese legal system, the planning policies, the urban management, as well as the geo-technologies, the relative scientific researches, the industries equipment, etc. [4-6]. As consequence, so many disasters and accidents have been reported in recent years, and have a tendency to increase. In the developed country, as in European, during the rapid development, the same phenomenon has also been reported [7]. Today, with the climate changes and other challenges, the sustainable development should be taken into consideration. The new technologies, such as the smart city, the big data, the AI could be helpful for the UUS exploitation for stratify the citizens and the stakeholders $[8,9]$.

The main objective of the current work is to review the progress of the exploitation of UUS in China. Firstly, the strategic demands of underground space in Chinese cities are analyzed. Then, the problems and difficult are discussed. Finally, the possible solutions are proposed.

\section{Strategic demand of UUS exploitation in China}

In the past 30 years, the urbanization in China has recovered hundreds of year's history of the developed countries. It is also one of the most important engines for Chinese economy. The UUS exploitation is closely related to the urbanization [10, 11]. Today, China's underground space development has also many strategic demands:

\subsection{Improvement of urban space resource utilization}

Urbanization rate in China has increased from $20.16 \%$ in 1981 to $56.10 \%$ in 2015 , and the national urban area increased from $7,000 \mathrm{~km}^{2}$ to $49,000 \mathrm{~km}^{2}$. Supposing an urbanization rate as $70 \%, 28,000 \mathrm{~km}^{2}$ of land resource is needed [12]. Although, China has sufficient land resource for this development theoretically, most cities in China, either the quantities of population or the density are not sustainable for the development [13]. The lack of infrastructures is evident, from the transportation to the parking, to the green space, etc. The underground rail transit network and the underground expressway network can significantly alleviate the traffic pressure in the city and replace $5 \%$ to $8 \%$ of urban road. If the 
proportion of parking spaces and vehicles in China's increase to 1.3 times, $1000 \mathrm{~km}^{2}$ is needed in the cities. The underground construction of half of the newly built parking lot can save $600 \mathrm{~km}^{2}$ of urban construction land. In addition, the underground and semi-underground of infrastructure (e.g. substations and sewage plants) can replace urban green space in large quantities.

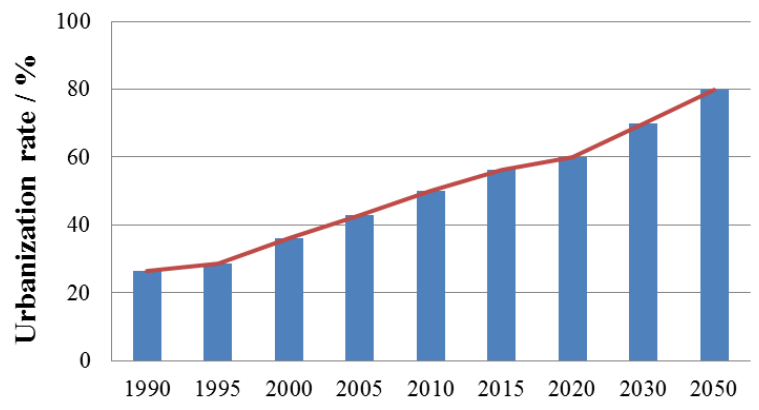

Time / year

Fig. 1. Urbanization rate forecast in China

\subsection{Urgent demands for solving "urban diseases"}

Urbanization is an inevitable trend in the development of human society [14]. However, the increase in urbanization rate means that more people are crowding into cities, which brings great challenges to the development of cities and is the main cause of "urban diseases". Developing UUS will help to solve the problems that Chinese cities are currently facing.

(a) Traffic jams and parking. Traffic jams is the common problems of Chinese cities, from large cities, as Beijing and Shanghai, to the small cities, the jams are frequently. As the density of population is relatively high in the urban area, the jam is inevitable. The underground transportation system, especially the public transportation system (metro, tramway, the underground bus network, etc) could be good solution. The underground parking is an alternative choice, not only for increasing the parking place, but also for the urban green area.

(b) Air pollution and urban environment. Automobile is currently considered the main source of air pollution and the greenhouse gas in major cities in China. It has great potential and significance in alleviating the air pollution problems and improving urban environment in China by developing underground space public transportation system and underground network.

(c) Improving infrastructure. Due to the low level of urbanization and the rapid expansion of cities, the quality of urban infrastructure needs to be improved in China. With the ambition projects of technical galleries (underground utility tunnel), all the systems (including, electricity, gas, water, communication, light, heat, etc.) has been integrated in 
the same gallery. The underground utility tunnel, not only facility the infrastructures' maintenance, but also increase their safety.

\subsection{Promoting urban economic growth}

In the past 30 years, the urbanization accelerated the economic growth. In the next years, it is the UUS, the new kinetic energy to stimulate economic growth, promotes industrial development and creates new jobs. In 2020, the urban rail transit system will double by that in 2015 , and the employs will increase by $18 \%$. By 2035, the total urban rail transit system in China is expected to reach or exceed $15,000 \mathrm{~km}$. These will undoubtedly encourage the sector of construction materials (e.g. steel and cement), machinery and equipment, and construction and management industries [15]. It is estimated that the output value of underground space utilization will reach 5 6 trillion yuan in 2030, which will form a new economic growth point in China's new era and help to improve urban employment and income levels.

\section{Issues of UUS exploitation in China}

The use of UUS before the reform and opening up of China is mainly based on the construction of civil defense projects (or military projects), with limited scale and single type. The use of UUS after the reform has entered an accelerated development stage, especially the rapid development of subway projects [16]. Since 2000, China has become the fastest growing country in the exploitation of underground space over the world. However, compared with the trend of exploitation of underground space in developed countries, there are still some gaps in the planning, conception, design and exploitation of the UUS.

\subsection{UUS development function lags behind and lacks development depth}

Nowadays, the exploitation of UUS in China is very fast, but the overall progress is still incomparable with the rate of urbanization $[17,18]$. In addition, the underground space utilization is relatively simple. Developmental stages of UUS in China were shown in Table 1. Nearly $60 \% \sim 80 \%$ of them are mainly used for underground parking. The underground space is arranged in a scattered point arrangement, and is not connected to each other. Moreover, most of UUS are within a depth of $30 \mathrm{~m}$, which will cause some constrains for further development. The main reason is that the master plan in most cities in China is far from meeting the needs of underground space planning and development, and the basic geological work supporting the development and management of underground space is still relatively weak. The current regional survey work is not comprehensive enough to grasp 
the geological characteristics, structure and geological parameters of deep underground space, which still has a big gap between the requirements for the transparent display of geological bodies. In addition, the sophisticated detection technology of deep underground space resources needs to be further studied, and it is still unable to fully meet the needs of supporting the development of underground space planning.

Table 1. Developmental stages of UUS in China

\begin{tabular}{|c|c|c|c|c|}
\hline $\begin{array}{l}\text { Developmental } \\
\text { stage }\end{array}$ & Function & Characteristic & $\begin{array}{l}\text { Depth } \\
/ \mathrm{m}\end{array}$ & $\begin{array}{l}\text { Representative } \\
\text { city }\end{array}$ \\
\hline Initialization & $\begin{array}{l}\text { Underground } \\
\text { parking, civil } \\
\text { defense }\end{array}$ & $\begin{array}{l}\text { Single unit construction, single } \\
\text { function and small scale }\end{array}$ & $<10$ & $\begin{array}{l}\text { Prefecture-level } \\
\text { cities }\end{array}$ \\
\hline Large-scale & Rail traffic & $\begin{array}{l}\text { Linear development along rail } \\
\text { traffic }\end{array}$ & $15 \sim 20$ & $\begin{array}{l}\text { Qingdao, } \\
\text { Xiamen }\end{array}$ \\
\hline Initial network & $\begin{array}{l}\text { Rail traffic nodes } \\
\text { and complexes }\end{array}$ & $\begin{array}{l}\text { The subway line begins to } \\
\text { cross the key utilization nodes } \\
\text { and underground complexes }\end{array}$ & 30 & $\begin{array}{l}\text { Shenzhen, } \\
\text { Tianjin }\end{array}$ \\
\hline Scale network & $\begin{array}{l}\text { Various public } \\
\text { facilities }\end{array}$ & $\begin{array}{l}\text { The subway network system is } \\
\text { perfect, including commercial, } \\
\text { transportation and municipal. }\end{array}$ & 50 & $\begin{array}{l}\text { Shanghai, } \\
\text { Beijing }\end{array}$ \\
\hline $\begin{array}{l}\text { Underground } \\
\text { eco-city }\end{array}$ & $\begin{array}{l}\text { Various } \\
\text { underground } \\
\text { facilities } \\
\text { integrated }\end{array}$ & $\begin{array}{l}\text { A fully functional and } \\
\text { ecological ecosystem }\end{array}$ & 200 & - \\
\hline
\end{tabular}

\subsection{UUS information isolation}

Compared with urban ground information management, the information of UUS involves planning management, land management, construction management, civil defense management, operation and maintenance management, environment and fire management, and so on. At present, the information management of urban municipal pipelines, integrated pipe corridors, underground rail transit, underground buildings, etc. is still relatively backward [19]. The integration of urban geological work and urban construction management is insufficient. Furthermore, there are information barriers between the technical and departmental departments, and the management system has not opened up the connection channels. Therefore, it is difficult to effectively provide scientific and practical urban geological basic data and achievements for urban construction.

The management of underground space in typical cities in China involves more than 20 units and departments, which presents a more dispersed and complex pattern and lack a 
clear coordination and coordination department [20]. Each management department assumes its own management functions. What's more, different departments have different management requirements, which may lead to complicated approval procedures, chaotic management, and unclear interest relationships. Therefore, the policies need to be improved to encourage the UUS exploitations.

\subsection{The underground space risk assessment and resilience}

The construction of underground projects will inevitably affect or even destroy the surrounding structures, geotechnical bodies and groundwater systems. The development of underground space faces different risks. In China, a complete risk assessment mechanism has not yet formed. The UUS exploitation is likely to cause a series of environmental and geological problems, such as ground deformation, land subsidence, groundwater pollution, etc. The occurrence of such problems is mainly due to the fact that the management system, the legislative issues, the standard, the norms for the exploitation of underground space in China are not yet sound enough to provide safe and effective guarantee for the exploitation of UUS. Among them, underground space planning, operation management and control planning, resource utilization policy guidance, three-dimensional development of land use planning system, underground space zoning development and guidance strategy, underground space land use planning indicators and planning implementation guarantees need to be further strengthened and improved.

\section{Development trends of UUS in China}

Nowadays, the urbanization in China will continue with the economic development. The exploitation of UUS is evident. In the same time, with the confrontation of many challenges and difficulties, the possible solutions adapting current situations should be proposed.

\subsection{Layered and networked planning layout}

With the rapid and separate development in the UUS in China, the most urgent problem for the further development in UUS is how to integrate the newly developed underground spaces with the existing underground buildings, generally separate with each other. Therefore, the long period guideline for a given city is particularly important. At the level of urban master planning, each city will combine the local geological characteristics and the direction of urban extension according to the future economic conditions and development needs. The UUS exploitation planning extends in not only the horizontal direction, but also the vertical direction. The UUS is discrete in different functional area with in the depth. Schematic illustration of layered development of underground space was presented in 
Figure 2 [14]. In fact, the layout of the future underground space is more possible as network. For the developed countries, they encounter also the same problems from last century. The experiences and the lessons could be helpful for the Chinese UUS exploitation. For example, the metro, the utility tunnel, the underground commercial center, etc.
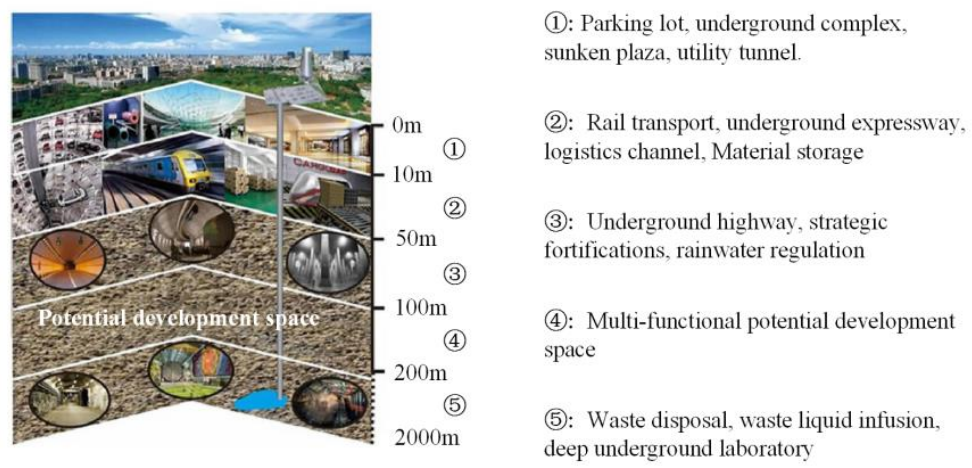

Fig. 2. Schematic illustration of layered development of underground space

\subsection{Humanization}

More considerations on the environmental characteristics of underground space and on the impact of underground space environment to human physiological and psychological levels [21] should be taken. As surrounding by the geo-formation, the UUS is considered as a closed space with limited accesses. The advantage is that it has good thermal isolation and consumes relative small quantity of energy for heating. The disadvantages are that the quality of the air and the humidity should be controlled for assuring the comfort and the safety of the user. The ventilation system is necessary, not only for the potential fire, but also for the daily operation and maintenance. With the increase in quality of life, besides of the safety in the UUS, the conformable is not the critical problem in the exploitation of UUS.

\subsection{Digital and intelligent management}

Large-scale construction and operation of UUS will generate massive data (e.g., planning, construction, operation, maintenance). At present, the digital and intelligent management in Chinese UUS systems is mainly based on GIS/BIM technology. However, GIS/BIM technology has some problems when it is applied in underground space, such as lack of geological model, analysis function, and data collection, difficulty in information transmission, collaborative work, and file compatibility. Strengthening the development of digital and intelligent management is crucial to the exploitation of UUS. 
The planning, design, construction, operation, maintenance, disaster prevention and safety management of UUS are inseparable from comprehensive understanding and accurate of basic data of UUS. The use of digital and intelligent methods to manage UUS data is an inevitable development trend. It is a multidisciplinary and interdisciplinary problem, and beyond the classic engineering problem. Especially for the construction and decision-making of UUS in nowadays, as well as the urban disaster prevention and emergency response in the underground space, which has a tendency to be more and more complicates $[22,23]$. The digital technologies and the conception of smart give the possible for the further development of the UUS. With the modern tools, such as the BIM, GIS, the $\mathrm{AI}$, the digital and intelligent management system will be implemented in phases and improved in practice. The resilience of UUS also will be augmented.

\section{Conclusions}

The paper has introduced an overview of progress on the exploitation of UUS in China, and the following conclusions can be drawn:

(1) Exploitation of underground space in China has many strategic. The exploitation of UUS can effectively improve the utilization of urban space resources, which is an urgent need to meet the challenges in the urbanization, and favorite for the durable urban economic growth.

(2) China has become the fastest growing country in exploitation of underground space in the world. However, there are still many deficiencies and problems in exploitation of UUS. Many efforts should be paid for planification, the information isolation and the risk assessment and resilience.

(3) The lessons and experiences learned from developed countries could be helpful for the China in the UUS exploitation. The future development of UUS exploitation in China should consider layered and networked planning, humanization, etc. The digital and intelligent management is inevitable in the further UUS exploitation.

\section{References}

1. D.V.L. Hunt, L.O. Makana, Jefferson I., C.D.F. Rogers, Tunn. Undergr. Space Technol. 55, 8-20 (2016)

2. R.L. Sterling, H. Admiraal, N. Bobylev, H. Parker, J.P. Godard, I. Vähäaho, T. Hanamura, Proc. Inst. Civ. Eng. Urban Design Plan. 165 (4), 241-254 (2012)

3. X.Z. Li, C. Li, A. Parriaux, W.B. Wu, H.Q. Li, L.P. Sun, C. Liu, Tunn. Undergr. Space Technol. 55, 59-66 (2016)

4. Q.H. Qing, Tunn. Undergr. Space Technol. 55, 280-289 (2016)

5. Z.L. Chen, J.Y. Chen, H. Liu, Z.F. Zhang, Tunn. Undergr. Space Technol. 71, 253- 
$270(2018)$

6. J. Liu, Y. Li, G.J. Zhang, Y.N. Liu, Constr. Build. Mater. 227, 116654 (2019)

7. P. Duffaut, Undergr. Space 5(2), 86-91 (1980)

8. L. He, Y. Song, S. Dai, K. Durbak, Tunn. Undergr. Space Technol. 32, 168-179 (2012)

9. W. Broere, Tunn. Undergr. Space Technol. 55, 245-248 (2016)

10. N. Bobylev, Land Use Pol. 26 (4), 1128-1137 (2009)

11. C.D.F. Rogers, Eng. Geol. Spec. Publ. 22 (1), 177-188 (2009)

12. K. Malik, Report of China human development, (UNDP in Asia and the Pacific, Beijing, 2013)

13. National Bureau of Statistics (NBS), Yearbook of Chinese cities, (China Statistics Press, Beijing 1985-2015) (in Chinese)

14. X.Z. Li, R. Wang, Q. Gu, D.K. Zhou, Y.X. Xin, Earth Sci. Front. 26(3), 32-38 (2019) (in Chinese)

15. C.S. Wang, C.H. Zhou, J.B. Peng, J. Fan, H.H. Zhu, X.Z. Li, G.H. Cheng, C.S. Dai, N.X. Xu, Earth Sci. Front. 26(3), 1-8 (2019) (in Chinese)

16. B.C. Liu, Chin. J. Rock Mech. Eng. 18(1), 109-111 (1999) (in Chinese)

17. J.B.M. Admiraal, Tunn. Undergr. Space Technol. 21 (3-4), 464-465 (2006)

18. P. Belanger, Tunn. Undergr. Space Technol. 22 (3), 272-292 (2007)

19. Z.H. Lv, X.M. Li, B.Y. Zhang, W.X. Wang, Y.Y. Zhu, J.X. Hu, S.Z. Feng, IEEE access 4, 407-415 (2016)

20. G.H. Chen, R. Wang, M.H. Zhao, J.W. Su, Y. Yang, X.B. Zhang, Earth Sci. Front. 26(3), 39-47 (2019) (in Chinese)

21. N. Ivanova, O. Ganzha, Proce. eng. 165, 1006-1015 (2016)

22. M. Casals, M. Gangolells, N. Forcada, M. Macarulla, A. Giretti, M. Vaccarini, Appl. Energy 166, 150-164 (2016)

23. P.P. Nelson, Tunn. Undergr. Space Technol. 55, 32-39 (2016) 